\title{
Cell Type-Specific, Presynaptic LTP of Inhibitory Synapses on Fast-Spiking GABAergic Neurons in the Mouse Visual Cortex
}

\author{
Abdolrahman Sarihi, ${ }^{1,2 *}$ Javad Mirnajafi-Zadeh, ${ }^{1,3 *}$ Bin Jiang, ${ }^{1,4}$ Kazuhiro Sohya, ${ }^{1,5}$ Mir-Shahram Safari, ${ }^{1}$ \\ Masoumeh Kourosh Arami, ${ }^{1}$ Yuchio Yanagawa, ${ }^{6,7}$ and Tadaharu Tsumoto ${ }^{1}$ \\ ${ }^{1}$ Brain Science Institute RIKEN, Wako 351-0198 Japan, ${ }^{2}$ Neurophysiology Research Center, Hamadan University of Medical Sciences, Hamadan, Iran, \\ ${ }^{3}$ Department of Physiology, Faculty of Medical Sciences, Tarbiat Modares University, Tehran, Iran, ${ }^{4}$ Neuroscience Research Center, Zhongshan School of \\ Medicine, Sun Yat-Sen University, Guangzhou 510080, Peoples Republic of China, ${ }^{5}$ PRESTO, Japan Science and Technology Agency, Tokyo 102-0075 Japan, \\ ${ }^{6}$ Gunma University Graduate School of Medicine, Maebashi, 371-8511 Japan, and ${ }^{7}$ CREST, Japan Science and Technology Agency, Tokyo 102-0075 Japan
}

Properties and plasticity of inhibitory synapses on fast-spiking (FS) GABAergic (FS-GABA) interneurons in layer II/III of the mouse visual cortex were examined in cortical slices by whole-cell recordings of IPSCs or IPSPs evoked by activation of presynaptic FS or non-FS GABAergic interneurons. Unitary IPSCs (uIPSCs) evoked by action potentials of FS-GABA neurons have shorter onset latency, faster rising slope, higher peak amplitude, and faster decay time than those evoked by action potentials of non-FS-GABA neurons. Tetanic activation of presynaptic FS-GABA neurons induced long-term potentiation (LTP) of uIPSCs, whereas that of presynaptic non-FS-GABA neurons did not induce LTP, indicating that long-term plasticity of inhibitory synapses on FS-GABA neurons is pathway specific. For further analysis of inhibitory synaptic plasticity, IPSPs evoked by electrical stimulation of an adjacent site in the cortex were recorded from FS-GABA neurons. Theta burst stimulation induced LTP of IPSPs in 12 of 14 FS-GABA neurons. The paired-pulse stimulation protocol and coefficient of variation analysis indicated that this form of LTP may be presynaptic in origin. Filling postsynaptic cells with $\mathrm{a} \mathrm{Ca}^{2+}$ chelator did not block the induction of LTP, suggesting no involvement of postsynaptic $\mathrm{Ca}^{2+}$ rise. Also, this form of LTP was dependent neither on metabotropic glutamate receptors nor voltage-gated $\mathrm{Ca}^{2+}$ channels of the $\mathrm{L}$ and $\mathrm{T}$ types. Further pharmacological analysis indicated that voltage-gated $\mathrm{Ca}^{2+}$ channels other than the $\mathrm{P} / \mathrm{Q}$ type, such as $\mathrm{N}$ and $\mathrm{R}$ types, were not involved in LTP, suggesting that P/Q-type channels are a candidate for factors inducing LTP of inhibitory synapses between FS-GABA neurons.

\section{Introduction}

Experience-dependent modification of visual cortical function is based not only on plasticity of excitatory synapses but also on plasticity of inhibitory synapses (Sillito et al., 1981; Hensch et al., 1998; Maffei et al., 2006). Long-term potentiation (LTP) is a form of synaptic plasticity that may be involved in such a modification of neuronal circuits in the visual cortex (Tsumoto, 1992; Bear, 2003). Most of the previous studies focused on LTP of excitatory synapses on pyramidal neurons in layer II/III or layer $\mathrm{V}$ of the cortex. Subsequently, LTP of GABAergic inhibitory synapses on pyramidal neurons in the cortex also attracted some interest

Received March 21, 2012; revised July 2, 2012; accepted July 28, 2012.

Author contributions: A.S. and T.T. designed research; A.S., J.M.-Z., B.J., K.S., M.-S.S., and M.K.A. performed research; Y.Y. contributed unpublished reagents/analytic tools; A.S., J.M.-Z., B.J., K.S., M.-S.S., M.K.A., and T.T. analyzed data; T.T. wrote the paper.

This study was supported in part by a Grant-in-Aid for Scientific Research from the Japan Society for the Promotion of Science to T.T. We thank Dr. A. Miyawaki for providing pCS2-Venus and Dr. H. Ozeki for reading the manuscript.

${ }^{*}$ A.S. and J.M.-Z. contributed equally to this work.

The authors declare no competing financial interests.

Correspondence should be addressed to Dr. Tadaharu Tsumoto, Brain Science Institute, RIKEN, 2-1 Hirosawa, Wako 351-0198, Japan. E-mail: tsumoto@brain.riken.jp.

DOI:10.1523/JNEUROSCI.1386-12.2012

Copyright $\odot 2012$ the authors $\quad 0270-6474 / 12 / 3213189-11 \$ 15.00 / 0$
(Komatsu and Iwakiri, 1993; Komatsu and Yoshimura, 2000; Holmgren and Zilberter, 2001). There is another possible locus of plasticity in inhibitory circuits, i.e., inhibitory synapses on GABAergic inhibitory interneurons. To our knowledge, there was no systematic study on long-term plasticity of this type of inhibitory synapses in the visual cortex.

GABAergic interneurons are classified functionally into at least two subtypes, fast-spiking (FS) and non-FS neurons, which may correspond approximately to basket cells and non-basket cells morphologically, and parvalbumin (PV)-positive and -negative interneurons neurochemically (DeFellipe, 1993; Kawaguchi and Kubota, 1997; Gonchar and Burkhalter, 1997; Markram et al., 2004; Ascoli et al., 2008). Therefore, inhibitory synapses on GABAergic interneurons might have no plasticity or a different type of plasticity if they do, depending on subtypes of presynaptic and postsynaptic GABAergic interneurons. This information is crucial for understanding functional properties of cortical neural circuits, because each subtype of interneurons is suggested to play distinct functional roles in the circuits (Buzsáki and Chrobak, 1995; Kawaguchi and Kubota, 1997; Somogyi et al., 1998; Freund, 2003; Markram et al., 2004).

Regarding mechanisms underlying LTP of excitatory synapses on pyramidal neurons in the visual cortex, its induction is known 
to depend on an increase in postsynaptic $\mathrm{Ca}^{2+}$ concentration through NMDA receptor channels (Artola and Singer, 1987; Kimura et al., 1989; Bear et al., 1992) or voltage-gated $\mathrm{Ca}^{2+}$ channels (VGCCs) (Grover and Teyler, 1990; Komatsu and Iwakiri, 1992) or on a release of $\mathrm{Ca}^{2+}$ from inositol triphosphate $\left(\mathrm{IP}_{3}\right)$ sensitive stores via an activation of metabotropic glutamate receptors (mGluRs) (Huemmeke et al., 2002; Wang and Daw, 2003). Also, LTP of excitatory synapses on GABAergic interneurons is dependent on an activation of mGluRs of type 5 in the mouse visual cortex (Sarihi et al., 2008). However, a question of what mechanism is involved in LTP of inhibitory synapses on GABAergic neurons if induced is not yet known at all.

In the present study we examined whether LTP is induced at inhibitory synapses on GABAergic interneurons of the FS type. To facilitate identification of GABAergic neurons in slice preparations, we used transgenic mice in which GABAergic neurons expressed fluorescent protein. We found that robust LTP was induced in inhibitory synapses on fast-spiking GABAergic (FSGABA) neurons in a pathway-specific manner, i.e., only in synapses connected with other FS-GABA neurons but not in synapses connected with non-FS-GABA neurons, and that presynaptic VGCCs of the P/Q-type are candidates for factors that are involved in LTP.

\section{Materials and Methods}

Slice preparation. Glutamate decarboxylase 67 (GAD67)-green fluorescent protein (GFP) ( $\Delta$ neo) knock-in mice (Sohya et al., 2007) or vesicular GABA transporter (VGAT)-Venus transgenic mice (Kameyama et al., 2010), aged from 19 to 23 postnatal days (P19-P23), were anesthetized with isoflurane (Abbott) and then decapitated. The brains were rapidly removed and placed in the cold oxygenated artificial CSF (ACSF). Coronal slices of the visual cortex (300 $\mu \mathrm{m}$ thick) were obtained using a tissue slicer (Vibratome 3000; Vibratome). All experimental procedures were carried out in accordance with the guidelines of the Animal Experimental Committee of RIKEN Brain Science Institute. Slices were placed in an incubating chamber of oxygenated ACSF at $31^{\circ} \mathrm{C}$ for at least $1 \mathrm{~h}$ before recording. The recording temperature was $30^{\circ} \mathrm{C}$. The ACSF had the following composition (in $\mathrm{mm}$ ): $124 \mathrm{NaCl}, 3.0 \mathrm{KCl}, 2.0 \mathrm{CaCl}_{2}, 1.0$ $\mathrm{MgCl}_{2}, 1.25 \mathrm{NaH}_{2} \mathrm{PO}_{4}, 26.0 \mathrm{NaHCO}_{3}$, and 10.0 glucose (pH 7.4). The ACSF was bubbled continuously with $95 \% \mathrm{O}_{2} / 5 \% \mathrm{CO}_{2}$. The flow rate of the ACSF was about $2.5 \mathrm{ml} / \mathrm{min}$.

Whole-cell recordings from GABAergic interneurons. Whole-cell recordings were made from GABAergic interneurons in layer II/III of the visual cortex under infrared differential interference contrast optics. GABAergic interneurons in cortical slices of GAD67-GFP knock-in or VGATVenus mice were visualized with an epifluorescence microscope (BX51WI, Olympus). We identified FS- and non-FS-GABAergic neurons by injecting depolarizing currents of $50-400 \mathrm{pA}$ for $500 \mathrm{~ms}$ as described in the Results section. In most of the experiments, IPSPs evoked by test stimulation of layer II/III at $0.05 \mathrm{~Hz}$ were recorded in the current-clamp mode in the presence of an antagonist for NMDA receptors, DL-2-amino-5-phosphonovaleric acid (APV, Sigma-Aldrich) at 100 $\mu \mathrm{M}$, and an antagonist for AMPA receptors, 6-cyano-7-nitroquinoxaline-2,3-dione (CNQX; Sigma-Aldrich) at $20 \mu \mathrm{m}$. In part of the experiments, IPSCs were recorded in the voltage-clamp mode at -70 $\mathrm{mV}$. IPSPs or IPSCs were recorded with a multiclamp amplifier (700B; Molecular Devices), filtered at $2-5 \mathrm{kHz}$, digitized at $10 \mathrm{kHz}$, and fed into a Pentium 4 personal computer with a digitizer computer interface (PCIMIO-16E-4, National Instruments). The analysis was made using Igor 4.01 program.

Recording electrodes were pulled from borosilicate glass capillary with filaments ( $0.86 \mathrm{~mm}$ inner diameter, $1.5 \mathrm{~mm}$ outer diameter). The resistance of these electrodes with the following internal solution was 5-7 $\mathrm{M} \Omega$. The composition of the internal solution was (in $\mathrm{mM}$ ) $120 \mathrm{KCl}, 10$ HEPES, 4 MgATP, and $0.3 \mathrm{Na}_{3} \mathrm{GTP}$ and adjusted to $\mathrm{pH} 7.25$ with $\mathrm{KOH}$. The osmolarity of the solution was $275-290 \mathrm{mOsm}$. The series resistance of the recording system in the voltage-clamp mode was measured at the beginning of the recording using a $10 \mathrm{mV}$ test pulse and checked when the recordings were switched to the voltage-clamp mode. The measured values were usually $14-25 \mathrm{M} \Omega$. The input resistance of neurons was continuously monitored throughout the recording by injecting hyperpolarizing test currents ( $-20 \mathrm{pA}$ for $100 \mathrm{~ms}$ ). The measured values were mostly $120-180 \mathrm{M} \Omega$ and usually very stable during recordings. If these values changed $>20 \%$, the recordings were stopped and the data were discarded. In the experiments in which postsynaptic $\mathrm{Ca}^{2+}$ was chelated, 1,2-bis-(2-aminophenoxy)ethane- $N, N, N^{\prime}, N^{\prime}$-tetraacetic acid (BAPTA) was added at the concentration of $10 \mathrm{~mm}$ to the internal solution of recording electrodes.

In part of the experiments, dual whole-cell recordings were performed to record unitary IPSCs (uIPSCs) of FS-GABA neurons in layer II/III of the visual cortex. For these recordings the composition of the internal solution was as follows (in mM): $120 \mathrm{KCl}, 10$ HEPES, $0.5 \mathrm{Na}_{3} \mathrm{GTP}, 4$ MgATP, 10 Na-phosphocreatine, and $0.2 \%$ biocytin at pH 7.2-7.4. The osmolarity of solution was $270-290 \mathrm{mOsm}$. To subdivide presynaptic GABAergic neurons into FS or non-FS neurons, they were held in the current-clamp mode and their firing properties were assessed by delivering $500 \mathrm{~ms}$ depolarizing current steps. After GABAergic neurons were classified into FS and non-FS neurons on the basis of their firing pattern, depolarizing currents (usually $<300 \mathrm{pA}$ for $5 \mathrm{~ms}$ ) were injected to evoke one action potential in presynaptic GABAergic neurons. Cells were not used for analysis if the resting membrane potential was more positive than $-50 \mathrm{mV}$, series resistance was $>25 \mathrm{M} \Omega$, the input resistance was $<$ $100 \mathrm{M} \Omega$, or if any of these parameters changed by $15 \%$ during data acquisition.

The following parameters of uIPSCs were measured in traces obtained by averaging 15-30 consecutive responses: onset latency (from the peak of presynaptic action potentials to the onset of UIPSC); peak amplitude (from the baseline to the peak of uIPSC); base-to-peak rising time (from the onset of UIPSC to its peak); and rising slope (slope of a fitting line from 10 to $90 \%$ after onset of uIPSC). Decay $\tau$ was measured by fitting a single exponential to the decay phase of the uIPSC.

LTP induction. IPSPs of GABAergic neurons in layer II/III of visual cortical slices were elicited by test stimulation at $0.05 \mathrm{~Hz}$ through a concentric bipolar stimulating electrode ( $125 \mu \mathrm{m}$ diameter, FHC) positioned in the same layer of the cortex (about $100 \mu \mathrm{m}$ from the recording electrode). The intensity of test stimulation was set at $50 \%$ for the maximal responses (30-80 $\mu \mathrm{A}$ for pulses of $0.1 \mathrm{~ms}$ duration). After recording baseline responses for $10 \mathrm{~min}$, theta burst stimulation (TBS) for $50 \mathrm{~s}$ was applied to layer II/III while postsynaptic membrane was clamped at -60 $\mathrm{mV}$. TBS consisted of 5 trains at $0.1 \mathrm{~Hz}$, each train of 10 bursts at $5 \mathrm{~Hz}$, and each burst of 4 pulses at $100 \mathrm{~Hz}$. The intensity and width of each pulse were the same as those of test pulse. Thereafter, responses to test stimulation at $0.05 \mathrm{~Hz}$ were recorded again for at least $30 \mathrm{~min}$.

In case of dual whole-cell recordings, trains of 30 presynaptic action potentials were elicited at $1 \mathrm{~Hz}$ to induce LTP of uIPSCs. In part of the dual whole-cell recordings, TBS-like trains of action potentials were generated in presynaptic cells. Postsynaptic cell recording was performed in the voltage-clamp mode to record uIPSCs at $-60 \mathrm{mV}$.

Analysis of coefficient of variation of EPSPs and paired-pulse ratio. The coefficient of variation (CV) of the peak amplitudes of IPSPs evoked by electrical stimulation was determined within the stationary period. The stationary periods were 5-10 min before TBS and 15-35 min after TBS, when the peak amplitude of IPSPs was stable. The value of $\mathrm{CV}^{-2}$ was corrected for the variance of the background noise, using the relation $\sigma^{2}$ $=\sigma^{2}$ (measured) $-\sigma^{2}$ (noise) (Faber and Korn, 1991). To measure the background noise we used $2 \mathrm{~ms}$ of traces before stimulus. Then, we calculated the normalized $\mathrm{CV}$ and mean to the respective value $(\mathrm{CV}$ $=\sigma / m$, where $\sigma$ is the standard deviation and $m$ is the mean). To assess a possible change after TBS, we used separate block of 15-30 (mostly 30) traces for baseline value before TBS and 30-60 (mostly 60) traces 15-35 min after TBS. The paired-pulse ratio was determined as the peak amplitude of averaged traces $(10-25$ sweeps $)$ of the second IPSP to that of the first IPSP evoked by paired-pulse stimulation at an interval of $100 \mathrm{~ms}$.

Drugs. Drugs were applied either through the perfusion medium or the internal solution of recording pipettes. When drugs were applied 
through the internal solution, control recordings using the internal solution alone or the vehicle (DMSO $0.1 \%$ in ACSF) alone were made in slices from the same mice as those used for test recordings. In case of the bath application, interleaved control recordings were made in slices without a drug from the same animals. As selective antagonists for respective types of glutamate receptors, we used the following drugs: APV (Sigma-Aldrich) at $100 \mu \mathrm{M}$ for NMDA receptors; CNQX (SigmaAldrich) at $20 \mu \mathrm{M}$ for AMPA receptors; ( $S)-(+)$ - $\alpha$-amino-4-carboxy-2methylbenzeneacetic acid (LY367385; Tocris Bioscience) at $100 \mu \mathrm{M}$ for the type 1 metabotropic glutamate receptors (mGluR1); and 2-methyl6-(phenylethynyl)pyridine hydrochloride (MPEP; Tocris Bioscience) at $10 \mu \mathrm{M}$ for the type 5 of metabotropic glutamate receptor (mGluR5). As blockers for VGCCs, we used the following substances: 1,4-dihydro-2,6dimethyl-4-(3-nitrophenyl)-3,5-pyridinedicarboxylic acid 2-methyloxyethyl 1-methyl ester (nimodipine; Tocris Bioscience) at $10 \mu \mathrm{M}$ for L-type; Ro40-5967/(1S,2S)-2-[2-[[3-(1H-benzimidazol-2 yl)propyl]] methyl-amino]-6-fluoro-1,2,3,4-tetrahydro-1-(1-methylethyl)-2-naphthalenyl methoxyaceto-acetate dihydrochloride (mibefradil dihydrochloride; Tocris Bioscience) at $100 \mu \mathrm{m}$ for T-type; $\omega$-conotoxin GVIA at $1 \mu \mathrm{M}$ for N-type; $\omega$-agatoxin-IVA at $0.5 \mu \mathrm{M}$ for P/Q type (Zaitsev et al., 2007); and SNX-482 (Peptide Institute, Osaka, Japan) at $0.3 \mu \mathrm{M}$ for $\mathrm{R}$ type (Newcomb et al., 1998). As a blocker for gap junction channels, we used (AS)-rel-a-(2R)-2perperidinyl-2,8-bis(trifluoromethyl)-4-quinolinemethanol monohydrochloride (mefloquine hydrochloride, SigmaAldrich) at $25 \mu \mathrm{M}$ (Cruikshank et al., 2004).

Statistical analysis. In the present study, values are given as mean \pm SEM unless otherwise mentioned. For statistical analysis, values before and after TBS obtained from the same cell and values between two groups of cells were compared with paired and unpaired $t$ tests, respectively, when the values showed the normal distribution. The statistical evaluation of normal distribution was made using the Kolmogorov-Smirnov test.

\section{Results}

In the present study we classified GABAergic interneurons into FS and non-FS types based on electrophysiological properties, as reported previously (Sarihi et al., 2008). In FS-GABA neurons, test electrical stimulation given to layer II/III at $0.05 \mathrm{~Hz}$ under blockade of AMPA and NMDA receptors elicited synaptic potentials with a relatively slow decay (Fig. $1 A$ ). The onset latency of these synaptic potentials was $3.1 \mathrm{~ms}$. The mean onset latency for the 14 FS-GABA neurons was $2.7 \pm 0.1$ (SEM) ms. Such a short latency and a very small fluctuation of the latency (usually within $0.1 \mathrm{~ms}$ ) indicated that the synaptic potentials were elicited monosynaptically. These potentials were almost completely blocked by an application of bicuculline, an antagonist for $\mathrm{GABA}_{\mathrm{A}}$ receptors (Fig. $1 B$ ). These results together indicated that the potentials evoked by test stimulation of layer II/III were IPSPs mediated by GABA. If a sign of run down of IPSPs or a marked change in input and/or series resistances of the recording system were detected, the recordings were stopped and the data obtained were discarded. In the present report, synaptic responses of non-FSGABA neurons were not analyzed.

\section{Induction of LTP of IPSPs or IPSCs recorded from FS-GABA neurons}

After recording baseline responses for at least $10 \mathrm{~min}$ we applied TBS to the same site as the test stimulation site, while postsynaptic membrane potentials were kept at $-60 \mathrm{mV}$ in the voltageclamp mode. We found that TBS induced persistent potentiation ( $>20 \mathrm{~min}$ ) of IPSPs in most of the FS-GABA neurons tested (Fig. $1 B)$. Such a persistent potentiation of IPSPs was defined as LTP when the initial rising slope of IPSPs 20-25 min after TBS was significantly ( $p<0.05$, paired $t$ test) larger than that of the baseline value before TBS. In the 14 FS-GABA neurons, the mean
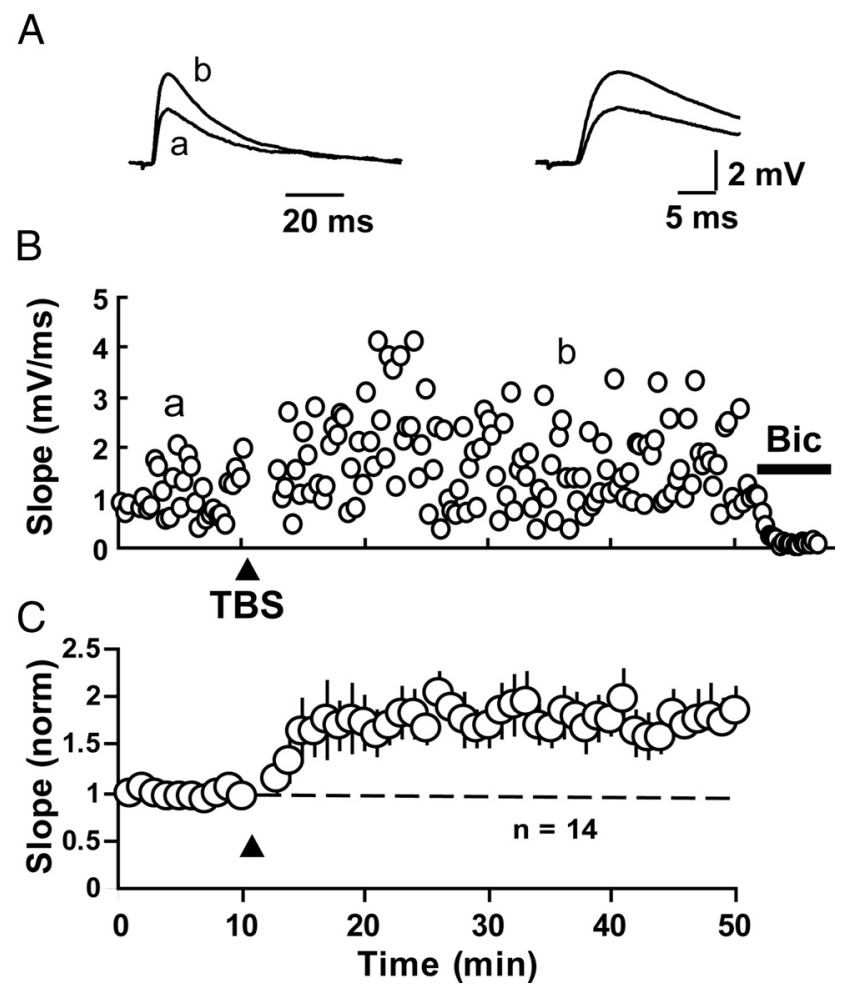

Figure 1. LTP of IPSPs recorded from FS-GABA neurons. $A$, Representative IPSPs evoked by electrical stimulation of cortical layer II/III before $(\boldsymbol{a})$ and after $(\boldsymbol{b})$ the induction of LTP. Each trace is an average of 15 consecutive traces. The initial phase of IPSP is shown in the right at the expanded time scale. $\boldsymbol{B}$, Time course of the rising slope of IPSPs. Theta-burst stimulation was given at the time indicated by the arrowhead. Bicuculline (BIC) was applied 40 min after TBS as indicated by the horizontal line, which led to disappearance of IPSPS. C, Time courses of the mean IPSP slopes recorded from 14 FS-GABA neurons. The slope was normalized to the value before TBS. Circles and vertical bars indicate means \pm SEMs. SEMs smaller than circles are not shown.

ratio of the IPSP slope 20-25 min after TBS to that before TBS was $1.79 \pm 0.04$ (Fig. $1 C$ ).

These evoked IPSPs are possibly mediated by mixed activation of axons of FS-type and non-FS-type GABAergic interneurons. To determine whether one or both of these pathways are involved in LTP of evoked IPSPs, we adopted dual whole-cell recordings from a given combination of GABAergic interneurons to record unitary IPSCs (uIPSCs). Action potentials generated in presynaptic FS or non-FS neurons induced uIPSCs in postsynaptic FS neurons as shown in Figure $2 A$. The uIPSCs were induced in 16 of $30 \mathrm{FS} \rightarrow$ FS neuron pairs and in 20 of 71 non-FS $\rightarrow$ FS neuron pairs within the cell-to-cell distance less than about $30 \mu \mathrm{m}$. We also recorded uIPSCs from non-FS-GABAergic neurons. These UIPSCs were not dealt with in the present study because of the limited number of cell pairs. As shown in the top traces of Figure $2 B$ and $C$, properties of uIPSCs elicited by action potentials of FSand non-FS-GABA neurons were quite different. In most cases, uIPSCs evoked by action potentials of FS-GABA neurons have shorter onset latency, faster rising slope, higher peak amplitude, and faster decay time than those of non-FS-GABA neurons (Table 1).

To test whether tetanic or repetitive activation of presynaptic cells induces LTP of uIPSCs in postsynaptic cells, we generated repetitive action potentials at $1 \mathrm{~Hz}$ for $30 \mathrm{~s}$ in presynaptic neurons in seven FS $\rightarrow$ FS cell pairs. This activation protocol was used to minimize a possible injury to presynaptic cells, and we found that such a repetitive stimulation (RS) of presynaptic FS-GABA neurons induced LTP of UIPSCs of postsynaptic FS-GABA neurons. 

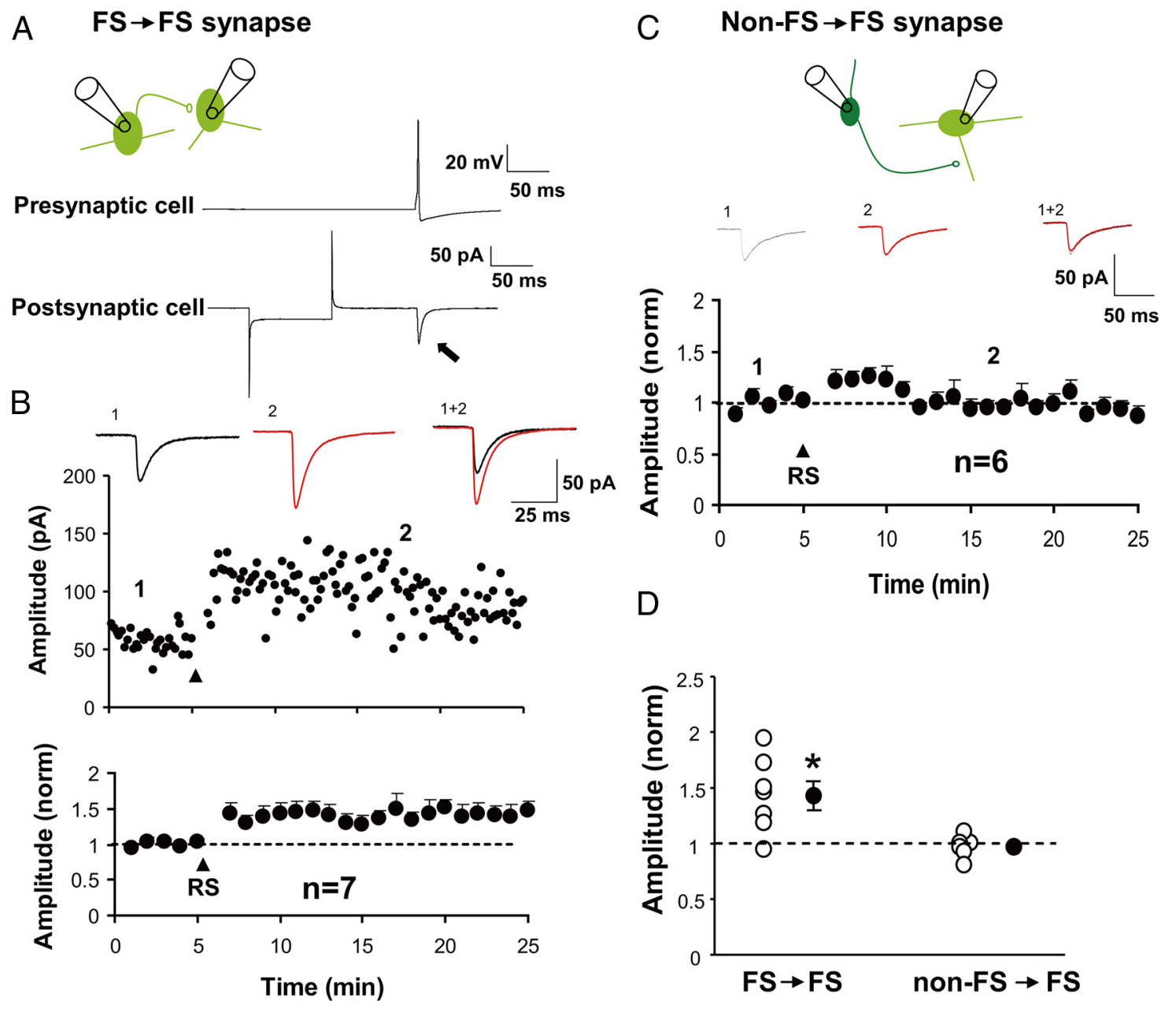

Figure 2. LTP of ulPSCs induced at FS $\rightarrow$ FS synapses but not at non-FS $\rightarrow$ FS synapses. A, Arrangement of dual whole-cell recordings from a FS-GABA neuron connected with another FS-GABA neuron, as schematically shown at top. At bottom is shown an example of IPSCs of postsynaptic cell (indicated by arrow in the bottom trace) evoked by action potentials generated in presynaptic cell (top trace). Large deflections in the lower trace were generated by current injection to monitor the input resistance of the cell. Each trace is an average of 30 consecutive records. $\boldsymbol{B}$, Traces at top show examples of ulPSCs recorded at the time point indicated by the same number in the below-plotted graph. Arrow head indicates the time when repetitive stimulation (RS) was given to presynaptic cells. Graph at bottom shows the time course of the mean uIPSC amplitudes recorded from seven FS-GABA neurons. The value was normalized to that before RS. Vertical bars indicate SEMs. SEMs smaller than circles are not shown. $C$, Arrangement of dual whole-cell recordings from a FS-GABA neuron connected with a non-FS-GABA neuron, as schematically shown at top. At bottom is shown the time course of mean amplitude of uIPSCs of six FS-GABA neurons evoked by action potentials of non-FS-GABA neurons. Examples of ulPSCs recorded at the time point indicated by the same number are shown above. Other conventions are the same as in $\boldsymbol{B}$. $\boldsymbol{D}$, The ratio of the amplitude of uIPSCs after RS to that before RS for each pair of cells of the types indicated in the abscissa. Asterisk $\left({ }^{*}\right)$ indicates statistically significant difference at $p<0.05$ (unpaired $t$ test).

Table 1. Unitary IPSC properties of the two types of inhibitory synapses (mean \pm SEM)

\begin{tabular}{lcll}
\hline & $\begin{array}{l}\mathrm{FS} \rightarrow \mathrm{FS} \\
(n=9)\end{array}$ & $\begin{array}{l}\text { Non-FS } \rightarrow \mathrm{FS} \\
(n=11)\end{array}$ & $\begin{array}{l}\text { Difference } \\
(p \text { value) }\end{array}$ \\
\hline Onset latency (ms) & $0.57 \pm 0.07$ & $1.00 \pm 0.12$ & 0.0099 \\
Peak amplitude (pA) & $129 \pm 34$ & $44.9 \pm 7.5$ & 0.0168 \\
Base-to-peak rising time (ms) & $2.94 \pm 0.13$ & $5.67 \pm 0.79$ & 0.0066 \\
Rising slope (pA/ms) & $69.7 \pm 17.7$ & $12.6 \pm 1.9$ & 0.0022 \\
Decay $\tau$ (ms) & $6.7 \pm 0.6$ & $16.7 \pm 2.0$ & 0.0004 \\
\hline
\end{tabular}

In a pair of cells shown in the top graph of Figure $2 B$, the peak amplitude of uIPSCs increased to 1.8 times the baseline 5-6 min after RS. Such a significant enhancement lasted until the end of pair recordings, although a slight decay was seen about 12 min after RS. The group data from the seven pairs of this combination of cells are shown in the bottom graph of Figure $2 \mathrm{~B}$. The mean amplitude $15-20$ min after RS normalized to that before RS was $1.43 \pm 0.13$, which was significantly ( $p<0.05$, paired $t$ test) larger than the baseline value. The values for each of the pairs are plotted in Figure $2 D$ (left). In case presynaptic neurons are non-FS-GABA neurons, on the other hand, a long-lasting enhancement of uIPSCs was not induced in FS-GABA neurons by RS of presynaptic neurons (Fig. 2C). The mean values of the post-RS amplitude normalized to pre-RS amplitude, $0.96 \pm 0.04$, were not different from the baseline values in the non-FS $\rightarrow$ FS pathway (Fig. $2 \mathrm{D}$, right).

In part of the dual whole-cell recording experiments, the TBS type of activation was given to presynaptic cells. As shown in the upper traces of each row of Figure $3 A$, a presynaptic FS-GABA neuron generated action potential trains of the TBS type (a burst of 4 spikes at $100 \mathrm{~Hz}$, a train of 10 bursts at an interval of $200 \mathrm{~ms}$, and 5 trains at $0.1 \mathrm{~Hz}$ ), although one or two action potentials were abortive in some bursts. In a postsynaptic FS-GABA neuron, uIPSCs were evoked in response to each presynaptic action potential, although the UIPSC amplitude decreased with the number of presynaptic spikes with substantial variability (bottom traces of each row of Fig. $3 A$ ). Such a TBS-like activation of a presynaptic FS-GABA neuron induced a long-lasting enhancement of the uIPSCs of a postsynaptic FS-GABA neuron (Fig. $3 B, C$ ). In all of 
A

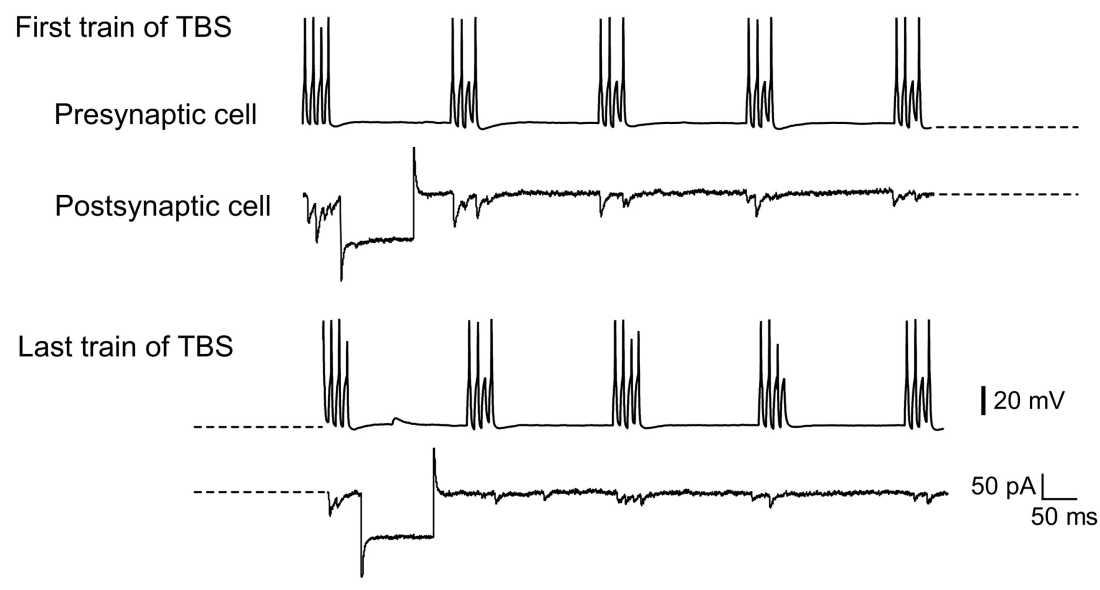

B
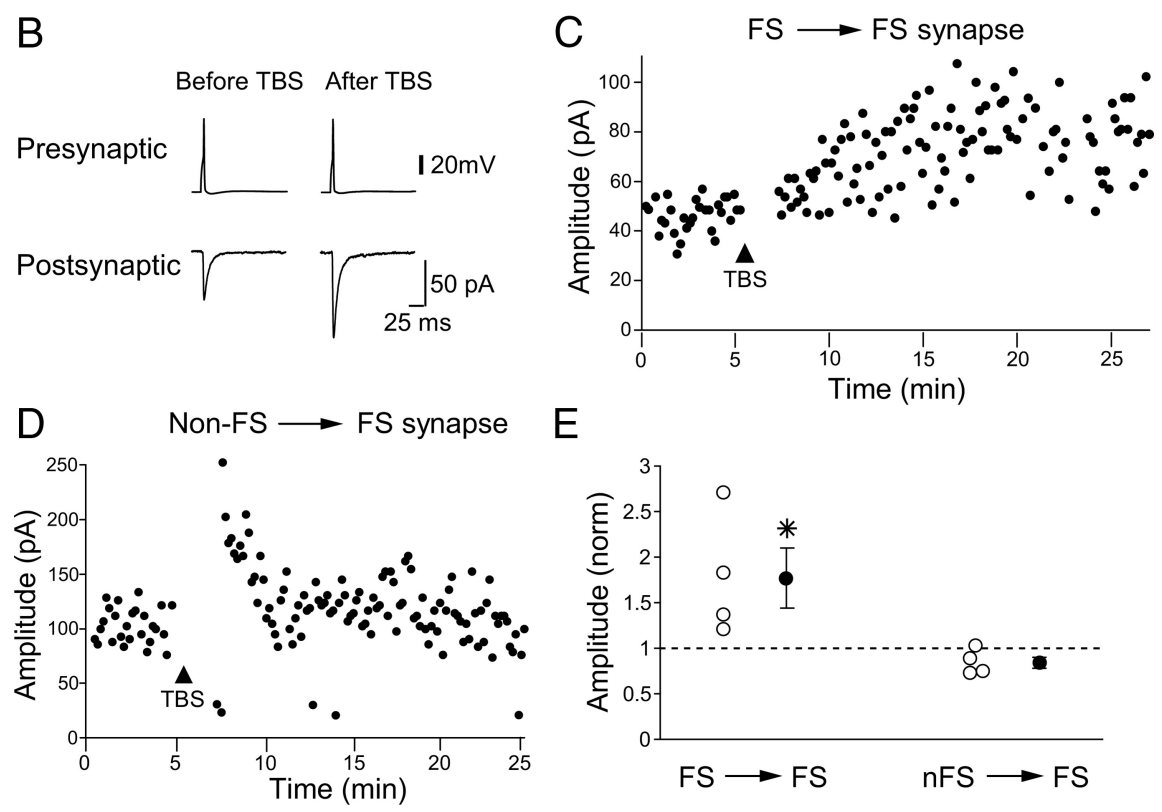

$\mathrm{E}$

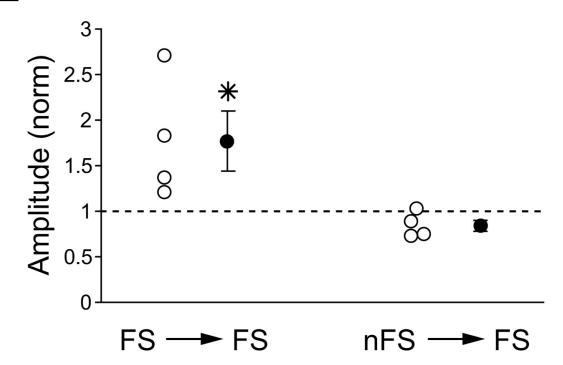

Figure 3. Induction of LTP by presynaptic action potential trains of the TBS type at FS $\rightarrow$ FS synapses. $A$, First five bursts of presynaptic action potential trains of the TBS type (upper traces of top row) and simultaneously recorded postsynaptic uIPSCS (lower traces of top row) and last five bursts of these action potential trains (upper traces of bottom row) and simultaneously recorded uIPSCS (lower traces of bottom row). Dotted lines indicate continuation of generation of presynaptic action potential trains and recording of postsynaptic uIPSCs. Large deflections in the lower traces were generated by current injection to monitor the input resistance of the postsynaptic cell. Vertical scales of $20 \mathrm{mV}$ and $50 \mathrm{pA}$ at the bottom right applies to all action potentials and uIPSCs, respectively. Time scale applies to all records. $\boldsymbol{B}$, An example of uIPSCs of the postsynaptic cell (lower traces) evoked by action potentials generated in the presynaptic cell (upper traces) before and after TBS. Each trace is an average of 15 consecutive records. $C$, The time course of change in the amplitudes of uIPSCs recorded at FS $\rightarrow$ FS synapses. This cell pair is the same as that shown in $\boldsymbol{A}$ and $\mathbf{B}$. Arrow head indicates the time when action potential trains of the TBS type was given to presynaptic cells. $\boldsymbol{D}$, The time course of change in the amplitudes of uIPSCs recorded at non-FS $\rightarrow$ FS synapses. Other conventions are the same as in $\boldsymbol{C}$. $\boldsymbol{E}$, The ratio of the amplitude of uIPSCs after TBS-like presynaptic activation to that before the activation for each pair of cells of the types indicated in the abscissa. Asterisk $\left(^{*}\right)$ indicates statistically significant difference at $p<0.05$ (unpaired $t$ test).

the four FS $\rightarrow$ FS cell pairs, the TBS-like presynaptic activation induced significant ( $p<0.05$, paired $t$ test) LTP of uIPSCs (Fig. $3 E$, left). We then generated a burst of action potentials of the TBS type in presynaptic non-FS-GABA neurons. This activation of non-FS-GABA neurons induced a transient and not long-lasting potentiation of uIPSCs in postsynaptic FS-GABA neurons (Fig. $3 D)$. None of the four non-FS $\rightarrow$ FS cell pairs showed LTP of uIPSCs (Fig. 3E, right).

These results suggest that TBS-induced LTP of electrically evoked IPSPs of FS-GABA neurons may mostly if not entirely reflect potentiation of uIPSCs at FS $\rightarrow$ FS synapses. Since stable long-lasting recordings were difficult in double-patch recordings from pairs of GABAergic neurons, subsequent pharmacological experiments were carried out mostly in IPSPs of FS-GABA neurons evoked by electrical stimulation of layer II/III of the cortex.

\section{No involvement of gap junction channels in LTP of IPSPs}

Because gap junction channels are known to operate between FS-GABA neurons in the neocortex (Galarreta and Hestrin, 1999; Gibson et al., 1999) and these channels in the rat thalamus are reported to show long-term changes in coupling efficacy (Landisman and Connors, 2005; Haas et al., 2011), there is a possibility that these channels might be involved in the present form of LTP. To test this possibility, we applied mefloquine, a blocker for gap junction channels, at $25 \mu \mathrm{M}$ (Cruikshank et al., 2004). To confirm that this concentration of mefloquine blocks gap junction channels in the present preparations, we applied mefloquine at $25 \mu \mathrm{M}$ to pairs of GABAergic neurons in dual whole-cell recordings. Three of $30 \mathrm{FS} \rightarrow$ FS neuron pairs and five of 71 non$\mathrm{FS} \rightarrow$ FS neuron pairs showed a detectable depolarization in presynaptic neurons in response to current injection into postsynaptic neurons (Fig. $4 A$, left). Five minutes after starting the application of mefloquine to those electrically coupled pairs of neurons, the potential change in presynaptic neurons completely disappeared (Fig. 4A, right), indicating that this concentration of mefloquine effectively blocks gap junction channels.

Then we tested whether this blocker affects the induction of LTP of evoked IPSPs induced by TBS of layer II/III of the cortex. As shown in Figure $4 B$, LTP of evoked IPSPs was induced in FS-GABA neurons by TBS during the application of mefloquine in the same way as in the control cells. The mean ratios of the IPSP slope 20-25 min after TBS to those before TBS were $1.64 \pm 0.05$ and $1.54 \pm 0.03$ with and without mefloquine, respectively. The difference between these two values was not significant $(p>0.05$, unpaired $t$ test). These results suggest that gap junction channels are not involved in LTP of IPSPs at FSGABA neurons in layer II/III of the mouse visual cortex.

\section{LTP of inhibitory synapses on FS-GABA neurons is not} dependent on mGluRs or postsynaptic $\mathrm{Ca}^{2+}$ rise

Recently we reported that LTP of excitatory synapses to FSGABA neurons is dependent on activation of the type 5 of mGluRs (Sarihi et al., 2008). To test whether this is the case for LTP of inhibitory synapses on FS-GABA neurons, we applied 

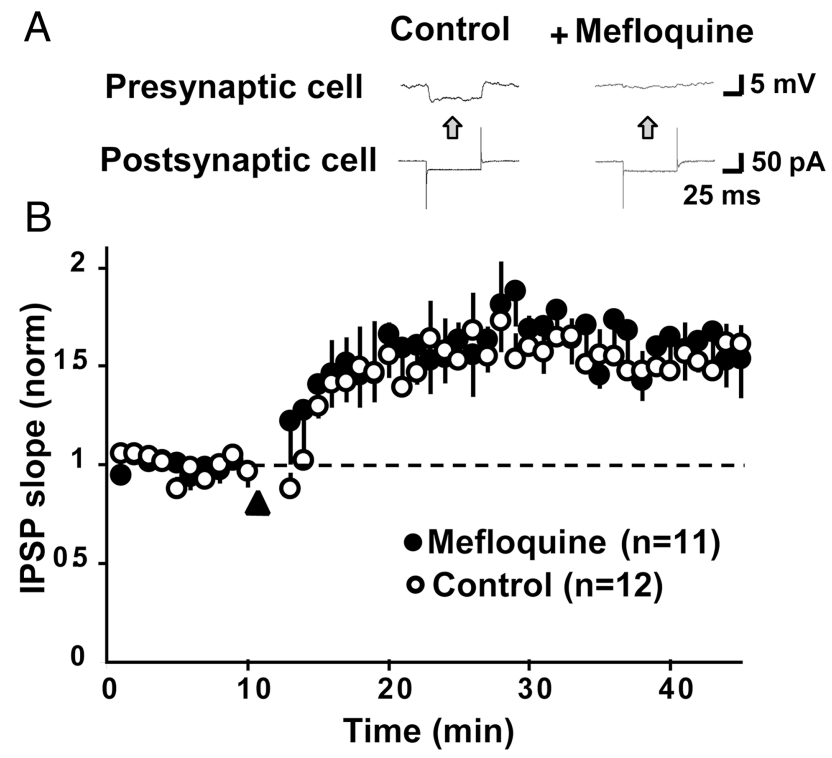

Figure 4. No involvement of gap junction channels in LTP of IPSPs. A, Membrane potential of a presynaptic FS-GABA neuron (top) and membrane currents of a companion postsynaptic FS-GABA neuron (bottom). Each trace is an average of 50 consecutive records. Hyperpolarizing currents (usually $<300 \mathrm{pA}$ for $100 \mathrm{~ms}$ ) were injected into postsynaptic cells. Left and right columns show records before and during application of mefloquine at $25 \mu \mathrm{m}$, respectively. $\boldsymbol{B}$, Time course of changes in the rising slope of IPSPs of FS-GABA neurons evoked by electrical stimulation of layer II/III of the cortex. The number of cells tested is shown in parentheses. Theta burst stimulation (TBS) was given at the time indicated by the arrowhead. Mean values normalized to those before TBS are plotted against time. Error bars indicate SEMs.

MPEP, an antagonist selective for mGluR5. We found that LTP was induced by TBS even in the presence of MPEP in the same way as in the control condition (Fig. 5A). The mean ratios of the IPSP slope $20-25 \mathrm{~min}$ after TBS to that before TBS were $1.35 \pm$ 0.05 and $1.32 \pm 0.06$ with and without MPEP, respectively. The difference between these two values was not significant $(p>0.05$, unpaired $t$ test). This result suggests that mGluR5 is not involved in LTP of inhibitory synapse on FS-GABA neurons. There is still a possibility that the type 1 of mGluRs, mGluR1, might be involved in the induction of LTP. To test this possibility we tested LY367385, an antagonist selective for mGluR1, in eight FS-GABA neurons and found that LTP of IPSPs was still induced in seven of the eight neurons. The mean ratios of the IPSP slope 20-25 min after TBS to that before TBS were $1.55 \pm 0.06(n=8)$ and $1.49 \pm$ $0.04(n=5)$ with and without LY367385, respectively. The difference between these two values was not significant $(p>0.05$, unpaired $t$ test).

We then addressed the question of whether the induction of LTP of inhibitory synapses on FS-GABA neurons is dependent on an increase in $\mathrm{Ca}^{2+}$ in postsynaptic sites. To answer this question, postsynaptic FS-GABA neurons were filled with a $\mathrm{Ca}^{2+}$ chelator, BAPTA, through recording pipettes. The concentration of BAPTA in the pipettes was $10 \mathrm{~mm}$, and recordings were not initiated until at least $5 \mathrm{~min}$ after rupture of cell membrane to allow BAPTA to spread in the neurons. In BAPTA-filled FS-GABA neurons we found that TBS clearly enhanced IPSPs in the same way as in control FS-GABA neurons. Group data obtained from eight BAPTA-filled FS-GABA neurons are shown together with those of seven control FS-GABA neurons (Fig. 5B). The mean ratios of the rising slope of IPSPs $20-25 \mathrm{~min}$ after TBS to that before TBS were $1.33 \pm 0.10$ in the eight BAPTA-filled neurons and $1.45 \pm$ 0.12 in the seven control neurons. The difference between these two values was not significant ( $p>0.05$, unpaired $t$ test). These
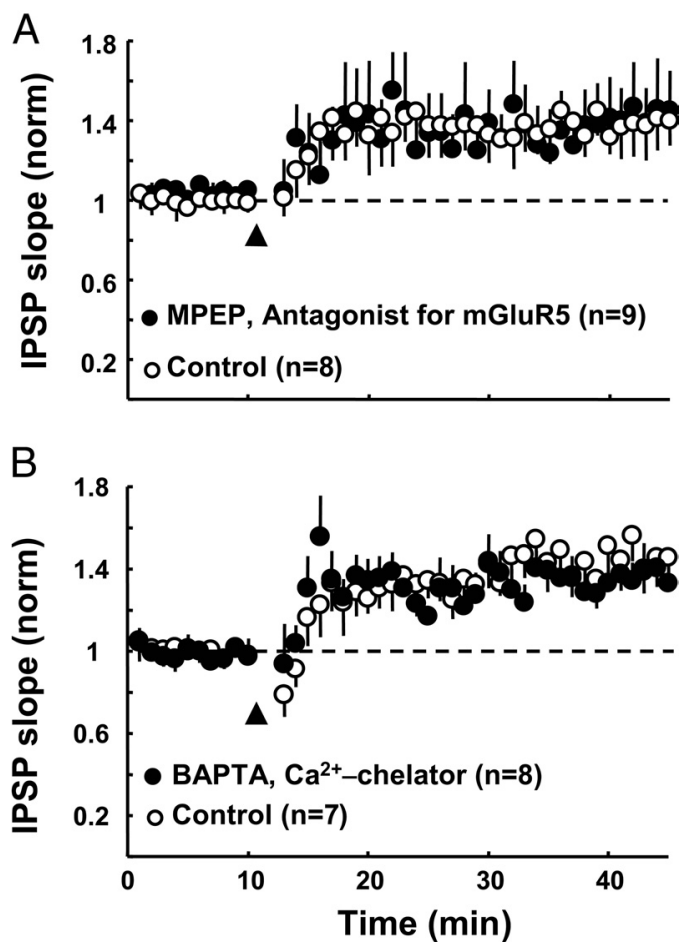

Figure 5. No dependency of LTP of FS $\rightarrow$ FS inhibitory synapses on mGluRs of the type 5 nor postsynaptic $\mathrm{Ca}^{2+}$ rise. $A$, Time course of the rising slope of IPSPs before and after TBS without (control) and with MPEP at $100 \mu \mathrm{M}$. MPEP was applied through the perfusion medium. The other conventions are the same as Figure $4 B$. B. Time course of the rising slope of IPSPs before and after TBS without (control) and with BAPTA, which was applied to postsynaptic cells through recording pipettes. The other conventions are the same as Figure $4 B$.

results indicate that an elevation of $\mathrm{Ca}^{2+}$ in postsynaptic FSGABA neurons is not necessary for the induction of LTP of inhibitory synapses on these neurons.

\section{Expression of LTP of inhibitory synapses on FS-GABA neurons is mainly presynaptic}

To determine whether LTP of inhibitory synapses on FS-GABA neurons is expressed presynaptically or postsynaptically, we initially analyzed the paired-pulse ratio (PPR) of IPSPs. In a FSGABA neuron shown in the top of Figure $6 A$, the first IPSP evoked by paired-pulse stimulation at an interval of $100 \mathrm{~ms}$ was enhanced after TBS, but the second IPSP was not proportionally changed so that the PPR was decreased. Although two exceptional cells showed an increase, the other seven cells showed a decrease in the PPR (Fig. 6A). The mean PPR of the nine cells after TBS $(0.77 \pm 0.04)$ was significantly $(p<0.05$, paired $t$ test $)$ smaller than that before TBS $(0.95 \pm 0.07)$. This result suggests that LTP may be ascribable to changes in presynaptic sites (Zucker, 1989).

To further address the presynaptic and postsynaptic issue we next made the coefficient of variation analysis (Faber and Korn, 1991; Sjöström et al., 2003). On the basis of a binomial model of synaptic transmission, functional changes in presynaptic sites are expected to be accompanied by a change in the CV of synaptic responses: the values of $\mathrm{CV}^{-2}$ that are plotted against the change in efficacy could be on the diagonal line if the release probability is low. On the other hand, if changes are located purely in postsynaptic sites, the values should be located on the horizontal line of 1.0. As shown in Figure $6 B$, the values of the nine FS-GABA neurons that showed significant LTP were located above the di- 

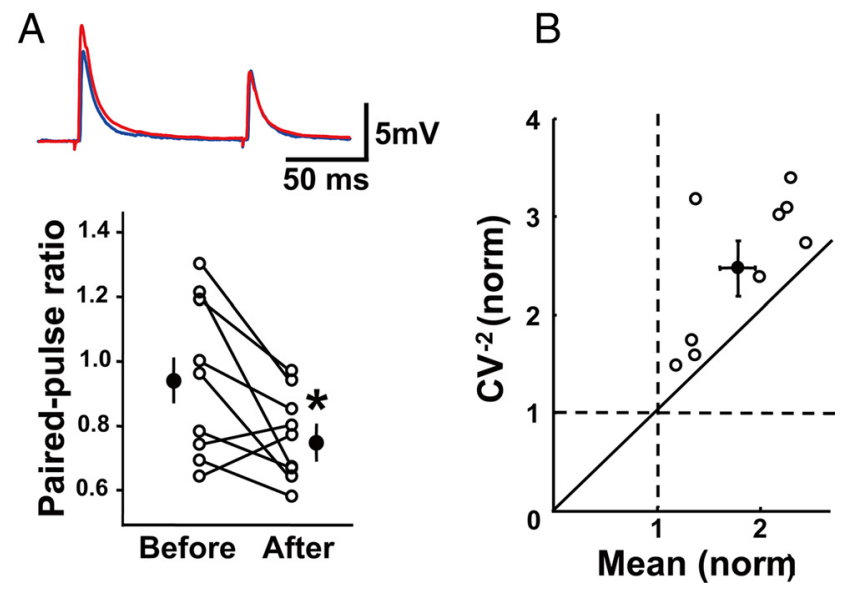

Figure 6. Presynaptic expression of LTP at inhibitory synapses on FS-GABA neurons. A, Top, examples of IPSPs evoked by paired-pulse stimulation at an interval of $100 \mathrm{~ms}$ before (blue trace) and after (red trace) the induction of LTP. Averages of 15 consecutive traces. In the bottom graph, the values of paired-pulse ratio before and after the induction of LTP are connected for each of the nine cell pairs. Filled circles and vertical bars indicate means \pm SEMs. $B, C V$ analysis of changes in IPSPs after the induction of LTP. Filled circle and vertical and horizontal bars indicate mean \pm SEMs, which were $2.51 \pm 0.26$ for the normalized value of $\mathrm{CV}^{-2}$ and $1.83 \pm$ 0.18 for the normalized mean value.

agonal line. Also, it is to be noted that the mean value of the normalized $\mathrm{CV}^{-2}$ for the nine cells was far from the level of 1.0. Altogether these results suggest that LTP of inhibitory synapses on most FS-GABA neurons is expressed presynaptically, although we cannot exclude the mixed presynaptic and postsynaptic changes in a fraction of FS-GABA neurons.

To further test whether the expression of LTP of inhibitory synapses at FS-GABA neurons is presynpatic or postsynaptic, we analyzed the amplitude and frequency of spontaneous IPSCs (sIPSCs). If the responsiveness of postsynaptic sites such as the sensitivity or density of postsynaptic receptors is changed, the amplitude of sIPSCs is expected to change. We found, however, that the mean amplitude of sIPSCs of the nine FS-GABA neurons was not significantly changed (Fig. 7A). If the presynaptic release probability is changed, one can expect that the frequency of sIPSCs will be changed, although the frequency could be contaminated by changes in firing of surrounding inhibitory neurons that are connected to presynaptic GABAergic neurons. We found that the frequency of sIPSCs was significantly increased after the induction of LTP (Fig. 7B). These observations on sIPSCs are consistent with the view that LTP of inhibitory synapses at FS-GABA neurons is presynaptic in origin.

\section{LTP of inhibitory synapses on FS-GABA neurons is not dependent on VGCCs of the L- and T-types}

As mentioned in the Introduction, there are some reports suggesting that different types of VGCCs are involved in the induction and maintenance of NMDA receptor-independent LTP of excitatory synapses on pyramidal cells in the visual cortex. This raises the following questions. Are VGCCs involved in LTP of inhibitory synapses on FS-GABA neurons? If so, what types of channels are involved? To address these questions, we initially applied nimodipine at $10 \mu \mathrm{M}$ as a blocker for VGCCs of the L type (Castillo et al., 1994; Kapur et al., 1998), and mibefradil at $100 \mu \mathrm{M}$ as a blocker for VGCCs of the T type (Martin et al., 2000; Cui et al., 2004).

An application of nimodipine slightly depressed IPSPs in all the cells tested. The application of mibefradil also slightly de-
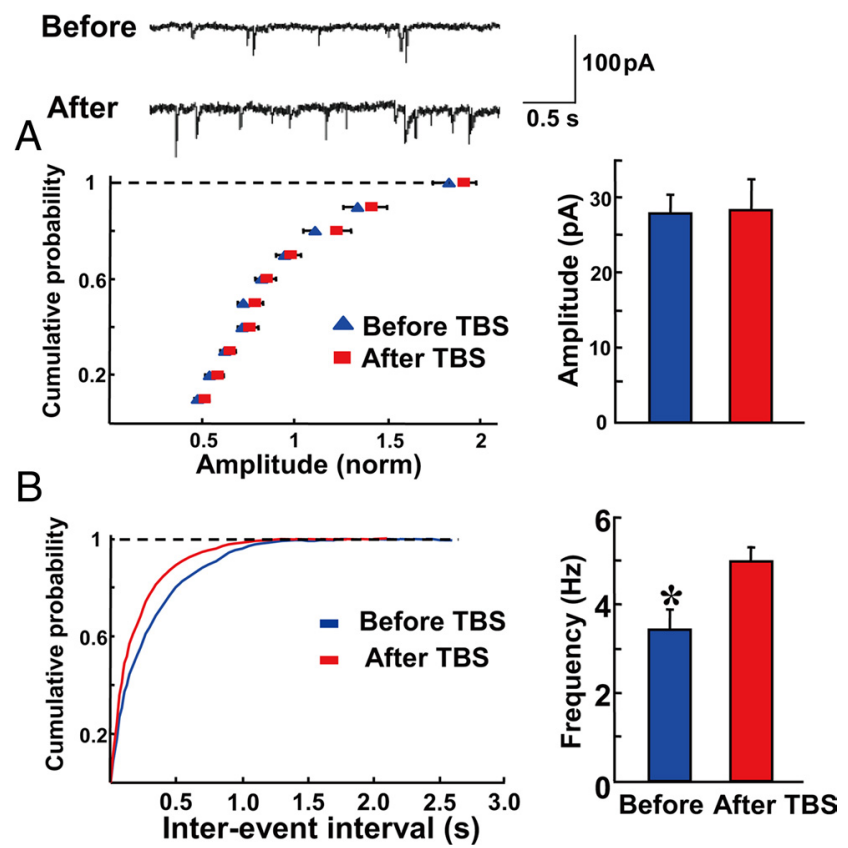

Figure 7. No change in the amplitude of spontaneous IPSCS but increase in their frequency. Top traces are examples of spontaneously generated IPSPs before and after TBS. $\boldsymbol{A}$, Cumulative probability of amplitude of IPSPs before (blue) and after (red) application of TBS. The amplitude was normalized to that before TBS application. Right, Mean values are indicated with SEM. The difference between the two columns is not significant $(p>0.05)$. $B$, Cumulative probability of intervals of spontaneous IPSPs before (blue) and after (red) application of TBS. Right, Mean values are indicated with SEM. Asterisk $\left(^{*}\right)$ indicates that the difference between the two columns is significant at $p<0.05$.

pressed IPSPs in about 70\% of the cells tested. In such a case, the intensity of test stimulation was increased so that the amplitude and rising slope of IPSPs were adjusted to attain the initial values. Then TBS was applied. As shown in Figure $8 A$, the application of nimodipine did not significantly reduce the magnitude of LTP of inhibitory synapses on FS-GABA neurons. The mean ratios of IPSP slopes 20-25 min after TBS to those before TBS were $1.33 \pm$ 0.10 in the control $(n=7)$ and $1.31 \pm 0.09$ with nimodipine $(n=$ $8)$. The difference between these two values was not significant $(p>0.05$, unpaired $t$ test). Also, mibefradil did not significantly reduce the magnitude of LTP of inhibitory synapses on FS-GABA neurons (Fig. $8 B$ ). The mean ratios of IPSP slopes $20-25 \mathrm{~min}$ after TBS to those before TBS were $1.39 \pm 0.17$ in the control $(n=$ $7)$, and $1.41 \pm 0.34$ with mibefradil $(n=6)$. Again, the difference was statistically insignificant ( $p>0.05$, unpaired $t$ test). These results indicate that LTP of inhibitory synapses on FS-GABA neurons may not be dependent on the activation of VGCCs of the Land T-types.

\section{A role of $P / Q$-type channels in inhibitory synaptic transmission to FS-GABA neurons and no involvement of} VGCCs other than the P/Q-type in LTP

To answer the question of whether VGCCs of the N or P/Q type that operate primarily in presynaptic sites are involved in GABA release from presynaptic terminals to FS-GABA neurons, we examined effects of $\omega$-conotoxin-GVIA ( $\omega$-CTx-GVIA), an N-type channel blocker, at $1 \mu \mathrm{M}$, and $\omega$-agatoxin-IVA ( $\omega$-AgaTx-IVA), a P/Q-type channel blocker, at $0.5 \mu \mathrm{M}$ (Wilson et al., 2001; Zaitsev et al., 2007; Kruglikov and Rudy, 2008). We found that $\omega$-CTxGVIA slightly but not significantly depressed IPSPs of FS-GABA neurons (Fig. 9A, red circles). The mean amplitude of IPSPs 

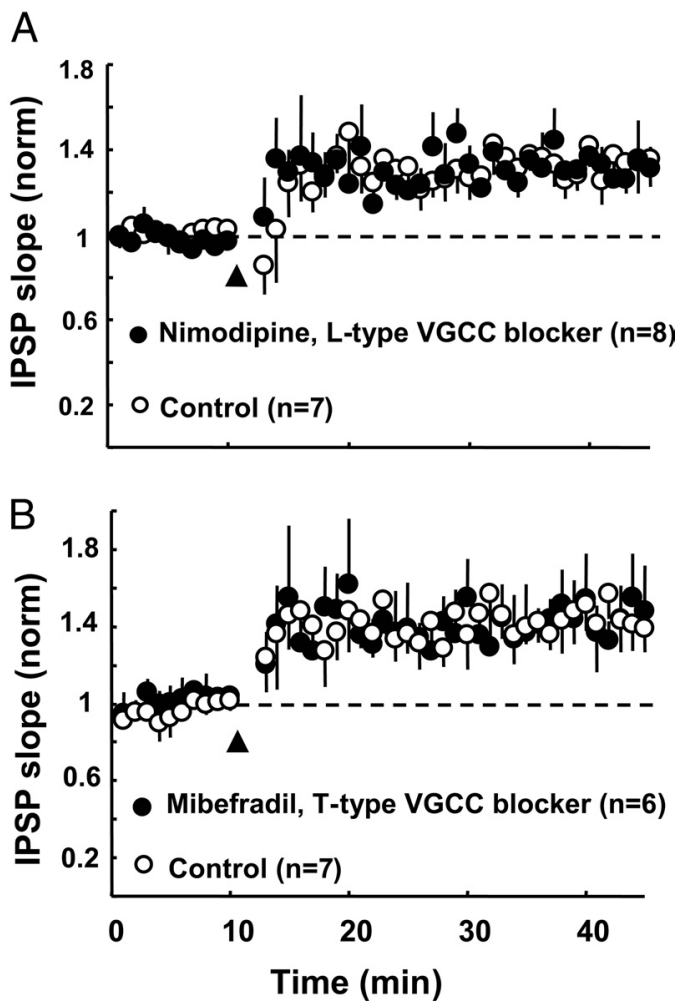

Figure 8. No involvement of voltage-gated $\mathrm{Ca}^{2+}$ channels of the $\mathrm{L}$ and $\mathrm{T}$ types in LTP at inhibitory synapses on FS-GABA neurons. $A$, Nimodipine, a blocker for VGCCs of the $L$ type, did not affect LTP of IPSPs recorded from FS-GABA neurons. The value of the rising slope of IPSPS was normalized to the pre-TBS value. Circles with vertical bars indicate mean with SEM. $\boldsymbol{B}$, Mibefradil, a blocker for VGCCs of the T type, did not affect LTP of inhibitory synapses on FSGABA neurons. Other conventions are the same as in $\boldsymbol{A}$.

15-20 min after the application of $\omega$-CTx-GVIA was $90.7 \pm 5.8 \%$ of the pre-application control value. On the other hand, $\omega$-AgaTx-IVA slowly but completely blocked IPSPs (Fig. 9A, black circles).

In addition to the $\mathrm{N}$ and $\mathrm{P} / \mathrm{Q}$ types, another type of VGCC, the $\mathrm{R}$ type, was reported to play a partial role in transmitter release in hippocampus and other regions of the brain (Dunlap et al., 1995). This type of VGCC was identified as resistant to both $\omega$-AgaTx-IVA and $\omega$-CTx-GVIA (Wu et al., 1998; Gasparini et al., 2001). The present result that $\omega$-AgaTx-IVA completely blocked IPSPs suggests that inhibitory synaptic transmission to FS-GABA neurons is mediated by VGCCs of the $\mathrm{P} / \mathrm{Q}$ type, but not by the $\mathrm{R}$ type. To confirm this suggestion, we tested a blocker for VGCCs of the R type, SNX-482, at 300 nm (Newcomb et al., 1998; Bhaukaurally et al., 2005) in seven FS-GABA neurons and found that this blocker did not significantly affect IPSPs in any of these neurons. The mean ratio of the IPSP amplitude 15-20 min after the application of SNX-482 for the seven cells was $1.07 \pm 0.02$ of the preapplication value (Fig. 9A, open triangles). These results indicate that VGCCs that are involved in inhibitory synaptic transmission to FS-GABA neurons are exclusively or almost exclusively of the P/Q type.

Since electrical stimulation of layer II/III of the cortex could activate both FS- and non-FS types of presynaptic GABAergic terminals, we then tested actions of $\omega$-AgaTx-IVA and $\omega$-CTXGVIA on the FS $\rightarrow$ FS type of unitary synaptic responses in dual whole-cell recordings. We found that $\omega$-AgaTx-IVA completely eliminated uIPSPs of FS $\rightarrow$ FS synapses (Fig. $8 B$, left traces). On
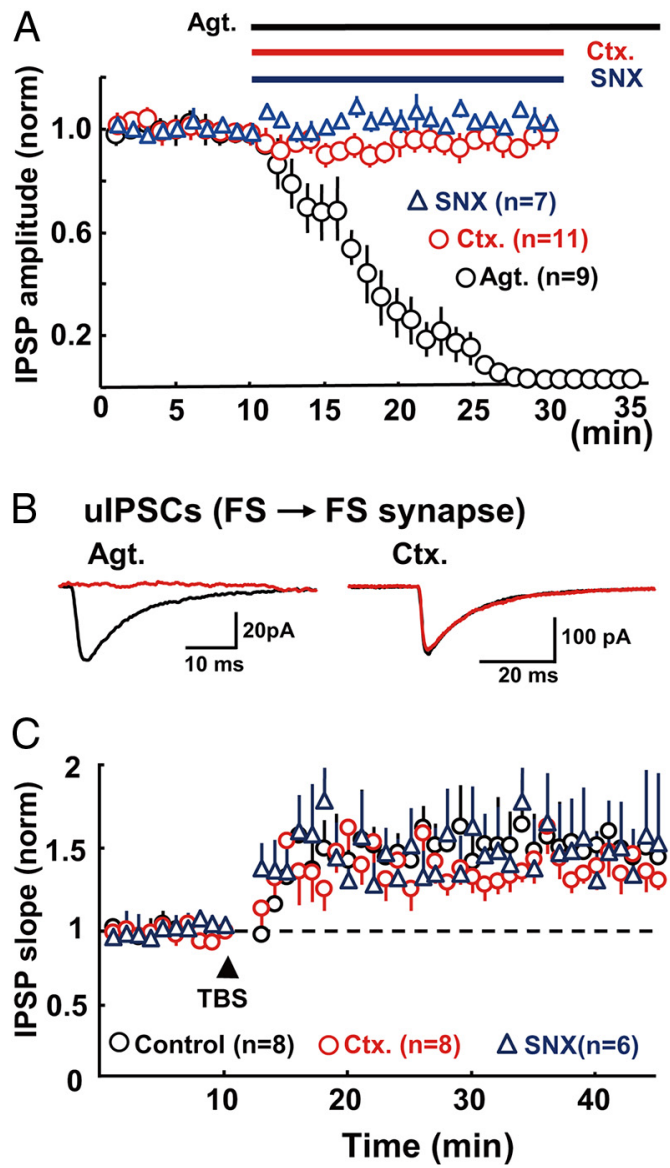

Figure 9. Contribution of $\mathrm{P} / \mathrm{Q}$-type channels to inhibitory synaptic transmission to FS GABA neurons and no involvement of $\mathrm{N}$ - nor R-type channels in LTP. $A$, No remarkable effects of $\omega$-conotoxin-GVIA (Ctx), a blocker for N-type channels, and SNX-482, a blocker for R-type channels, but a strong blocking action of $\omega$-agatoxin-IVA (Agt), a blocker for $\mathrm{P} / \mathrm{Q}$-type channels, on IPSPs evoked by test stimulation at $0.05 \mathrm{~Hz}$. The amplitudes of IPSPs were normalized to those before blocker application. Each blocker was applied as indicated by horizontal bars. $\boldsymbol{B}$, Examples of uIPSCs at FS-GABA $\rightarrow$ FS-GABA synapses before (black traces) and 5-10 min after (red traces) starting application of the blockers indicated at top. Each trace is an average of 30 consecutive records. C, Time courses of the rising slope of IPSPs before and after TBS with $\omega$-conotoxin-GVIA (red circles), and SNX482 (triangles) and without any blocker (black circles).

the other hand, $\omega$-CTX-GVIA did not reduce the amplitude of uIPSPs (Fig. $8 B$, right traces). Such a complete blocking action of $\omega$-AgaTx-IVA was seen in all of the four FS $\rightarrow$ FS synapses tested, whereas almost no effect of $\omega$-CTx-GVIA was observed in all of the six synapses of this type.

Finally, we addressed a question of whether the $\mathrm{N}$ or R type of VGCCs or both are involved in LTP of inhibitory synapses on FS-GABA neurons, even if they are not involved in basal synaptic transmission. To test this, we applied TBS during the administration of the respective blocker for VGCCs of the $\mathrm{N}$ and $\mathrm{R}$ types, and found that TBS induced LTP of IPSPs on FS-GABA neurons in the presence of each blocker (Fig. 9C). The mean ratios of the IPSP slope after TBS to that before TBS were $1.47 \pm 0.13$ with $\omega$-CTx-GVIA, $1.57 \pm 0.31$ with SNX482 , and $1.58 \pm 0.24$ without any drug (control). The former two values were not significantly different from the control value ( $p>0.05$, unpaired $t$ test). This result suggests that the $\mathrm{N}$ and $\mathrm{R}$ types of VGCCs are not involved in LTP of inhibitory synapses on FS-GABA neurons. 


\section{Discussion \\ Induction of LTP of inhibitory synapses on GABAergic interneurons}

LTP of GABAergic synaptic transmission has been extensively studied in the visual cortex (Komatsu and Iwakiri, 1993; Komatsu, 1994; Maffei et al., 2006), hippocampus (Grunze et al., 1996; McLean et al., 1996; Caillard et al., 1999; Gubelline et al., 2001; Patenaude et al., 2003), and other regions of the brain (for review, see Maffei, 2011). However, all of these studies, except for the one on brainstem dopamine neurons (Nugent et al., 2007), reported LTP of inhibitory synapses on pyramidal or excitatory principal neurons. To our knowledge, no study has reported the induction of LTP of inhibitory synapses on GABAergic inhibitory interneurons in the cerebral cortex. In the present study we have demonstrated that LTP of inhibitory synaptic transmission to FS-GABA neurons is induced by tetanic stimulation of presynaptic FSGABA neurons. On the other hand, LTP was not induced in FS-GABA neurons by the same parameters of tetanic stimulation of non-FS-GABA neurons. These results suggest that long-term synaptic plasticity of inhibitory synapses on GABAergic interneurons is specific to a particular presynaptic interneuron subtype. This suggestion seems to be in line with a recent study on shortterm plasticity, which reported that FS to FS inhibitory synapses in layer IV of the mouse somatosensory cortex showed strong paired-pulse depression, whereas somatostatin (SOM)-positive neuron to FS neuron synapses showed very weak or insignificant depression (Ma et al., 2012), although mechanisms for short- and long-term synaptic plasticity are not necessarily the same.

\section{Two types of inhibitory inputs to FS-GABA neurons}

In dual whole-cell recordings we found that uIPSCs evoked in FS-GABA neurons by action potentials of partner FS-GABA neurons have shorter latency, larger amplitudes, and faster rise and decay times than those evoked by action potentials of non-FSGABA neurons. This seems consistent with the previous observations that basket cells, which are mostly PV-positive and of the FS type, make synaptic contacts with somatic or perisomatic regions of other interneurons, whereas calretinin-positive, SOMpositive, or other "dendrite-targeting" interneurons, which are mostly of the non-FS type, make synaptic contact with relatively distal part of dendrites of interneurons in the neocortex and hippocampus (Gulyás et al., 1996; Kawaguchi and Kubota, 1997; Tamas et al., 1998; Somogyi et al., 1998; Gonchar and Burkhalter, 1999; Tamas et al., 2000; Freund, 2003; Thomson and Lamy, 2007). A recent study reported that uIPSCs of synapses from FS to other FS neurons had shorter latency and slower rise and decay times than those from SOM-positive neurons to FS neurons in layer IV of the mouse somatosensory cortex (Ma et al., 2012). The reported mean latencies of uIPSCs $(0.64 \mathrm{~ms}$ for $\mathrm{FS} \rightarrow$ FS synapses and $0.93 \mathrm{~ms}$ for $\mathrm{SOM} \rightarrow$ FS synapses) are similar to those of the present study $(0.57 \mathrm{~ms}$ for $\mathrm{FS} \rightarrow \mathrm{FS}$ synapses and $1.00 \mathrm{~ms}$ for non-FS $\rightarrow$ FS synapses), although the rise and decay times are different. This discrepancy may be ascribable to the difference in the methods of measuring the rise and decay times of uIPSCs (see Materials and Methods) and/or in the area and layers of the cortex (layer II/III of visual cortex versus layer IV of somatosensory cortex).

\section{Presynaptic expression of LTP of inhibitory synapses on FS-GABA neurons}

The present analysis of potentiated IPSCs with the paired-pulse stimulation protocol and the calculation of $\mathrm{CV}$ indicated that
LTP of inhibitory synapses on FS-GABA neurons may be presynaptic in origin. In layer II/III of the rat visual cortex it was reported that LTP of inhibitory synapses of FS-GABA $\rightarrow$ pyramidal neurons was induced when firing of the former neurons was elicited 200-300 ms after bursting activation of postsynaptic cells (Holmgren and Zilberter, 2001). In layer V of the rat visual cortex, however, it was reported that the induction of LTP of IPSPs of pyramidal cells was not dependent on postsynaptic membrane potentials (Komatsu, 1994). Subsequently, Komatsu (1996) reported that postsynaptic mechanisms such as activation of $\mathrm{GABA}_{\mathrm{B}}$ and monoamine receptors and $\mathrm{IP}_{3}$-induced $\mathrm{Ca}^{2+}$ release were involved in the induction of LTP, although the involvement of $\mathrm{GABA}_{\mathrm{B}}$ receptors was not observed in layer II/III of the visual cortex in another study (Holmgren and Zilberter, 2001). In the latter study it was reported that postsynaptic loading with an effective $\mathrm{Ca}^{2+}$ chelator blocked LTP of inhibitory synapses on pyramidal cells (Holmgren and Zilberter, 2001).

The present study on inhibitory synapses on FS-GABA neurons demonstrated, however, that filling postsynaptic cells with the $\mathrm{Ca}^{2+}$ chelator did not block the induction of LTP. Also, repetitive or tetanic activation of presynaptic FS-GABA neurons induced LTP of uIPSCs of postsynaptic FS-GABA neurons in the presence of the blockers for NMDA and AMPA receptors, indicating that glutamate receptors of the ionotropic types are not involved in LTP of inhibitory synapses on FS-GABA neurons. Glutamate receptors of the metabotropic types that were reported to operate in the hippocampus and visual cortex (mGluR1 and 5) are also not involved in the present type of LTP. Thus, it is reasonable to conclude that the expression site of LTP of inhibitory synapses on FS-GABA neurons and the underlying mechanism are different from those of LTP of inhibitory synapses on excitatory neurons, at least in layer II/III of the mouse visual cortex.

\section{Types of voltage-gated $\mathrm{Ca}^{2+}$ channels involved in presynaptic LTP}

In the present study we found that VGCCs of the P/Q type, but not $\mathrm{N}$ nor $\mathrm{R}$ type, are involved in GABA release from axon terminals of presynaptic FS-GABA to postsynaptic FS-GABA neurons at the basal synaptic transmission. This seems to be consistent with the previous observation that VGCCs of the P/Q type, but not the $\mathrm{N}$ type, mediate GABA release from FS interneurons to pyramidal cells in the rat frontal cortex, although postsynaptic neurons were excitatory in this report (Zaitsev et al., 2007).

Regarding long-term synaptic plasticity, we found that VGCCs of the L and T types are not involved in LTP of inhibitory synaptic transmission to FS-GABA neurons. The present results also indicate that VGCCs of the $\mathrm{N}$ or R type do not participate in LTP at this type of inhibitory synapses on FS-GABA neurons. To our knowledge VGCCs are classified into five types in the brain: T, L, N, P/Q, and R types (Dunlap et al., 1995; Reuter, 1996). Thus, VGCCs of the P/Q type remain to be candidates for the factors that are involved in the induction of LTP of inhibitory synaptic transmission to FS-GABA neurons.

Since the blocker for P/Q-type channels completely abolishes basal synaptic transmission, it is not possible to test whether LTP itself is affected by the blocker. In dual whole-cell recordings we found that LTP is induced only at FS $\rightarrow$ FS synapses that are mediated by VGCCs of the P/Q type. Therefore, it seems possible to suggest that this type of VGCC may play a primary, if not exclusive, role in LTP of inhibitory synapses on FS-GABA neurons in layer II/III of the mouse visual cortex, although we cannot com- 
pletely exclude the possibility that other presynaptic factors might be involved in this type of LTP.

\section{Functional significance of LTP of inhibitory synapses in cortical circuits}

In the cerebral neocortex, FS-GABA neurons such as PV-positive basket cells are reported to receive afferent inputs directly or indirectly from the thalamus and suggested to exert feedforward inhibition on adjacent pyramidal cells as well as to exert feedback inhibition via axon collaterals of pyramidal cells (Kawaguchi and Kubota, 1997; Somogyi et al., 1998; for review see Isaacson and Scanziani, 2011). These inhibitory circuits are thought to play a role in stability of pyramidal cell activity, formation of receptive fields, selectivity of responses, synchronization of neuron activities, and other functions in the adult cortex (Alitto and Dan, 2010; Maffei, 2011; Isaacson and Scanziani, 2011). These functions are implemented by inhibitory circuits, including excitatory synapses on GABAergic interneurons. These excitatory synapses on GABAergic interneurons show the spike time-dependent or Hebbian type of LTP, as reported previously (Lamsa et al., 2005; Sarihi et al., 2008, Perez et al., 2001; for review, see Maffei, 2011). This potentiation of inhibitory circuits may last for a long time. To prevent such a long-lasting activation of inhibitory circuits from being excessively enhanced, other FS-GABA neurons may suppress activity of interneurons at the presynaptic level.

GABAergic interneurons are proposed to play a key role in the synchronization of many pyramidal cells in the cerebral cortex, as mentioned above. In particular, it is suggested that PV-positive, FS basket cells control synchronized outputs of cortical principal cells because of the specific innervation pattern on pyramidal cell bodies (Cobb et al., 1995; Kawaguchi and Kubota, 1997; Kawaguchi, 2001; Freund, 2003) or the interconnectivity between those GABAergic neurons through electrical and chemical synapses (Galarreta and Hestrin, 2002). Thus, LTP of inhibitory synapses on FS-GABA neurons and subsequent long-lasting suppression of interneurons may play a role in reduction or cessation of synchronized activity of cortical pyramidal neurons. In this context, it is tempting to interpret that cholinergic projections to non-FS-GABA neurons such as SOM-positive interneurons (Kawaguchi, 1997, for review, see Lawrence, 2008) may play a role in switching synchronization or desynchronization of cortical pyramidal cells through non-long lasting modifiability of non-FS-GABA $\rightarrow$ FS-GABA synapses, although we have no direct evidence for this possibility in the present study.

\section{References}

Alitto HJ, Dan Y (2010) Function of inhibition in visual cortical processing. Curr Opin Neurobiol 20:340-346.

Artola A, Singer W (1987) Long-term potentiation and NMDA receptors in rat visual cortex. Nature 330:649-652.

Ascoli GA, Alonso-Nanclares L, Anderson SA, Barrionuevo G, BenavidesPiccione R, Burkhalter A, Buzsáki G, Cauli B, Defelipe J, Fairén A, Feldmeyer D, Fishell G, Fregnac Y, Freund TF, Gardner D, Gardner EP, Goldberg JH, Helmstaedter M, Hestrin S, Karube F, et al. (2008) Petilla terminology: nomenclature of features of GABAergic interneurons of the cerebral cortex. Nat Rev Neurosci 9:557-568.

Bear MF (2003) Bidirectional synaptic plasticity: from theory to reality. Philos Trans R Soc Lond B Biol Sci 358:649-655.

Bear MF, Press WA, Connors BW (1992) Long-term potentiation in slices of kitten visual cortex and the effects of NMDA receptor blockade. J Neurophysiol 67:841-851.

Bhaukaurally K, Panatier A, Poulain DA, Oliet SH (2005) Voltage-gated $\mathrm{Ca}^{2+}$ channel subtypes mediating GABAergic transmission in the rat supraoptic nucleus. Eur J Neurosci 21:2459-2466.

Buzsáki G, Chrobak JJ (1995) Temporal structure in spatially organized neuronal ensembles: a role for interneuronal networks. Curr Opin Neurobiol 5:504-510.

Caillard O, Ben-Ari Y, Gaiarsa JL (1999) Long-term potentiation of GABAergic synaptic transmission in neonatal rat hippocampus. J Physiol 518:109-119.

Castillo PE, Weisskopf MG, Nicoll RA (1994) The role of $\mathrm{Ca}^{2+}$ channels in hippocampal mossy fiber synaptic transmission and long-term potentiation. Neuron 12:261-269.

Cobb SR, Buhl EH, Halasy K, Paulsen O, Somogyi P (1995) Synchronization of neuronal activity in hippocampus by individual GABAergic interneurons. Nature 378:75-78.

Cruikshank SJ, Hopperstad M, Younger M, Connors BW, Spray DC, Srinivas M (2004) Potent block of Cx36 and Cx50 gap junction channels by mefloquine. Proc Natl Acad Sci U S A 101:12364-12369.

Cui G, Okamoto T, Morikawa H (2004) Spontaneous opening of T-type $\mathrm{Ca}^{2+}$ channels contributes to the irregular firing of dopamine neurons in neonatal rats. J Neurosci 24:11079-11087.

DeFelipe J (1993) Neocortical neuronal diversity: chemical heterogeneity revealed by co-localization studies of classical neurotransmitters, neuropeptides, calcium binding proteins and cell surface molecules. Cereb Cortex 3:273-289.

Dunlap K, Luebke JI, Turner TJ (1995) Exocytotic $\mathrm{Ca}^{2+}$ channels in mammalian central neurons. Trends Neurosci 18:89-98.

Faber DS, Korn H (1991) Applicability of the coefficient of variation method for analyzing synaptic plasticity. Biophys J 60:1288-1294.

Freund TF (2003) Interneuron diversity series: rhythm and mood in perisomatic inhibition. Trends Neurosci 26:489-495.

Galarreta M, Hestrin S (1999) A network of fast-spiking cells in the neocortex connected by electrical synapses. Nature 402:72-75.

Galarreta M, Hestrin S (2002) Electrical and chemical synapses among parvalbumin fast-spiking GABAergic interneurons in adult mouse neocortex. Proc Natl Acad Sci U S A 99:12438-12443.

Gasparini S, Kasyanov AM, Pietrobon D, Voronin LL, Cherubini E (2001) Presynaptic R-type calcium channels contribute to fast excitatory synaptic transmission in the rat hippocampus. J Neurosci 21:8715-8721.

Gibson JR, Beierlein M, Connors BW (1999) Two networks of electrically coupled inhibitory neurons in neocortex. Nature 402:75-79.

Gonchar Y, Burkhalter A (1997) Three distinct families of GABAergic neurons in rat visual cortex. Cereb Cortex 7:347-358.

Gonchar Y, Burkhalter A (1999) Connectivity of GABAergic calretininimmunoreactive neurons in rat primary visual cortex. Cereb Cortex 9:683-696.

Grover LM, Teyler TJ (1990) Two components of long-term potentiation induced by different patterns of afferent activation. Nature 347:477-479.

Grunze HC, Rainnie DG, Hasselmo ME, Barkai E, Hearn EF, McCarley RW, Greene RW (1996) NMDA-dependent modulation of CA1 local circuit inhibition. J Neurosci 16:2034-2043.

Gubellini P, Ben-Ari Y, Gaïarsa JL (2001) Activity- and age-dependent GABAergic synaptic plasticity in the developing rat hippocampus. Eur J Neurosci 14:1937-1946.

Gulyás AI, Hájos N, Freund TF (1996) Interneurons containing calretinin are specialized to control other interneurons in the rat hippocampus. J Neurosci 16:3397-3411.

Haas JS, Zavala B, Landisman CE (2011) Activity-dependent long-term depression of electrical synapses. Science 334:389-393.

Hensch TK, Fagiolini M, Mataga N, Stryker MP, Baekkeskov S, Kash SF (1998) Local GABA circuit control of experience-dependent plasticity in developing visual cortex. Science 282:1504-1508.

Holmgren CD, Zilberter Y (2001) Coincident spiking activity induces longterm changes in inhibition of neocortical pyramidal cells. J Neurosci 21:8270-8277.

Huemmeke M, Eysel UT, Mittmann T (2002) Metabotropic glutamate receptors mediate expression of LTP in slices of rat visual cortex. Eur J Neurosci 15:1641-1645.

Isaacson JS, Scanziani M (2011) How inhibition shapes cortical activity. Neuron 72:231-243.

Kameyama K, Sohya K, Ebina T, Fukuda A, Yanagawa Y, Tsumoto T (2010) Difference in binocularity and ocular dominance plasticity between GABAergic and excitatory cortical neurons. J Neurosci 30:1551-1559.

Kapur A, Yeckel MF, Gray R, Johnston D (1998) L-type calcium channels are required for one form of hippocampal mossy fiber LTP. J Neurophysiol 79:2181-2190. 
Kawaguchi Y (1997) Selective cholinergic modulation of cortical GABAergic cell subtypes. J Neurophysiol 78:1743-1747.

Kawaguchi Y (2001) Distinct firing patterns of neuronal subtypes in cortical synchronized activities. J Neurosci 21:7261-7272.

Kawaguchi Y, Kubota Y (1997) GABAergic cell subtypes and their synaptic connections in rat frontal cortex. Cereb Cortex 7:476-486.

Kimura F, Nishigori A, Shirokawa T, Tsumoto T (1989) Long-term potentiation and $N$-methyl-D-aspartate receptors in the visual cortex of young rats. J Physiol 414:125-144.

Komatsu Y (1994) Age-dependent long-term potentiation of inhibitory synaptic transmission in rat visual cortex. J Neurosci 14:6488-6499.

Komatsu Y (1996) $\mathrm{GABA}_{\mathrm{B}}$ receptors, monoamine receptors, and postsynaptic inositol triphosphate-induced $\mathrm{Ca}^{2+}$ release are involved in the induction of long-term potentiation at visual cortical inhibitory synapses. J Neurosci 16:6342-6352.

Komatsu Y, Iwakiri M (1992) Low-threshold $\mathrm{Ca}^{2+}$ channels mediate induction of long-term potentiation in kitten visual cortex. J Neurophysiol 67:401-410.

Komatsu Y, Iwakiri M (1993) Long term modification of inhibitory synaptic transmission in developing visual cortex. Neuroreport 4:907-910.

Komatsu Y, Yoshimura Y (2000) Activity-dependent maintenance of longterm potentiation at visual cortical inhibitory synapses. J Neurosci 20:7539-7546.

Kruglikov I, Rudy B (2008) Perisomatic GABA release and thalamocortical integration onto neocortical excitatory cells are regulated by neuromodulators. Neuron 58:911-924.

Lamsa K, Heeroma JH, Kullmann DM (2005) Hebbian LTP in feed-forward inhibitory interneurons and the temporal fidelity of input discrimination. Nat Neurosci 8:916-924.

Landisman CE, Connors BW (2005) Long-term modulation of electrical synapses in the mammalian thalamus. Science 310:1809-1813.

Lawrence JJ (2008) Cholinergic control of GABA release: emerging parallels between neocortex and hippocampus. Trends Neurosci 31:317-327.

Ma Y, Hu H, Agmon A (2012) Short-term plasticity of unitary inhibitoryto-inhibitory synapses depends on the presynaptic interneuron subtype. J Neurosci 32:983-988.

Maffei A (2011) The many forms and function of long term plasticity at GABAergic synapses. Neural Plast 2011: 254724.

Maffei A, Nataraj K, Nelson SB, Turrigiano GG (2006) Potentiation of cortical inhibition by visual deprivation. Nature 443:81-84.

Markram H, Toledo-Rodriguez M, Wang Y, Gupta A, Silberberg G, Wu C (2004) Interneurons of the neocortical inhibitory system. Nat Rev Neurosci 5:793-807.

Martin RL, Lee JH, Cribbs LL, Perez-Reyes E, Hanck DA (2000) Mibefradil block of cloned T-type calcium channels. J Pharmacol Exp Ther 295:302-308.

McLean HA, Caillard O, Ben-Ari Y, Gaiarsa JL (1996) Bidirectional plasticity expressed by GABAergic synapses in the neonatal rat hippocampus. J Physiol 496:471-477.

Newcomb R, Szoke B, Palma A, Wang G, Chen X, Hopkins W, Cong R, Miller J, Urge L, Tarczy-Hornoch K, Loo JA, Dooley DJ, Nadasdi L, Tsien RW, Lemos J, Miljanich G (1998) Selective peptide antagonist of the class E calcium channel from the venom of the tarantula Hysterocrates gigas. Biochemistry 37:15353-15362.

Nugent FS, Penick EC, Kauer JA (2007) Opioids block long-term potentiation of inhibitory synapses. Nature 446:1086-1090.

Patenaude C, Chapman CA, Bertrand S, Congar P, Lacaille JC (2003) $\mathrm{GABA}_{\mathrm{B}}$ receptor- and metabotropic glutamate receptor-dependent cooperative long-term potentiation of rat hippocampal $\mathrm{GABA}_{\mathrm{A}}$ synaptic transmission. J Physiol 553:155-167.

Perez Y, Morin F, Lacaille JC (2001) A Hebbian form of long-term potentiation dependent on mGluRla in hippocampal inhibitory interneurons. Proc Natl Acad Sci U S A 98:9401-9406.

Reuter H (1996) Diversity and function of presynaptic calcium channels in the brain. Curr Opin Neurobiol 6:331-337.

Sarihi A, Jiang B, Komaki A, Sohya K, Yanagawa Y, Tsumoto T (2008) Metabotropic glutamate receptor type 5-dependent long-term potentiation of excitatory synapses on fast-spiking GABAergic neurons in mouse visual cortex. J Neurosci 28:1224-1235.

Sillito AM, Kemp JA, Blakemore C (1981) The role of GABAergic inhibition in the cortical effects of monocular deprivation. Nature 291:318-320.

Sjöström PJ, Turrigiano GG, Nelson SB (2003) Neocortical LTD via coincident activation of presynaptic NMDA and cannabinoid receptors. Neuron 39:641-654.

Sohya K, Kameyama K, Yanagawa Y, Obata K, Tsumoto T (2007) GABAergic neurons are less selective to stimulus orientation than excitatory neurons in layer II/III of visual cortex, as revealed by in vivo functional $\mathrm{Ca}^{2+}$ imaging in transgenic mice. J Neurosci 27:2145-2149.

Somogyi P, Tamás G, Lujan R, Buhl EH (1998) Salient features of synaptic organization in the cerebral cortex. Brain Res Rev 26:113-135.

Tamás G, Somogyi P, Buhl EH (1998) Differentially interconnected networks of GABAergic interneurons in the visual cortex of the cat. J Neurosci 18:4255-4270.

Tamás G, Buhl EH, Lörincz A, Somogyi P (2000) Proximally targeted GABAergic synapses and gap junctions synchronize cortical interneurons. Nat Neurosci 3:366-371.

Thomson AM, Lamy C (2007) Functional maps of neocortical local circuitry. Front Neurosci 1:19-42.

Tsumoto T (1992) Long-term potentiation and long-term depression in the neocortex. Prog Neurobiol 39:209-228.

Wang XF, Daw NW (2003) Long term potentiation varies with layer in rat visual cortex. Brain Res 989:26-34.

Wilson RI, Kunos G, Nicoll RA (2001) Presynaptic specificity of endocannabinoid signaling in the hippocampus. Neuron 31:453-462.

Wu L-G, Borst JG, Sakmann B (1998) R-type $\mathrm{Ca}^{2+}$ currents evoke transmitter release at a rat central synapse. Proc Natl Acad Sci U S A 95:4720-4725

Zaitsev AV, Povysheva NV, Lewis DA, Krimer LS (2007) PQ-type, but not $\mathrm{N}$-type, calcium channels mediate GABA release from fast-spiking interneurons to pyramidal cells in rat prefrontal cortex. J Neurophysiol 97:3567-3573.

Zucker RS (1989) Short-term synaptic plasticity. Annu Rev Neurosci 12:1331. 